$\xi=-1$

\title{
Retardation of Mild Steel Corrosion in Analogous Schiff Bases with Different Electronic Environments
}

\author{
Syaidah Athirah Dzolin ${ }^{1}$, Hadariah Bahron ${ }^{1}$, Yusirie Mohd ${ }^{1}$, Nor Zakiah Nor Hashim ${ }^{2}$ \\ and Nurul Huda Abdul Halim ${ }^{3}$ \\ ${ }^{1}$ Faculty of Applied Sciences, Universiti Teknologi MARA (UiTM), 40450, Shah Alam, Selangor, Malaysia \\ ${ }^{2}$ Faculty of Applied Sciences, Universiti Teknologi MARA (UiTM), 35400, Tapah Road, Tapah, Perak, Malaysia \\ ${ }^{3}$ Faculty of Applied Sciences, Universiti Teknologi MARA (UiTM), 72000, Kuala Pilah, Negeri Sembilan \\ *Corresponding author E-mail: syaidahzolin@yahoo.com
}

\begin{abstract}
Two Schiff bases namely (E)-2-((phenylimino)methyl) phenol (SA1) and (E)-2-methoxy-6-((phenylimino)methyl) phenol (SA2) were produced via reaction of phenylamine with 2-hydroxybenzaldehyde and 2-hydroxy-3-methoxybenzaldenyde, respectively. The structures were elucidated through spectral and physicochemical techniques of melting point, elemental analysis $(\mathrm{C}, \mathrm{H}$ and $\mathrm{N}),{ }^{1} \mathrm{H} \mathrm{Nuclear}$ Magnetic Resonance (NMR) and Infrared (IR) spectroscopy. The distinctive $v(\mathrm{C}=\mathrm{N})$ and $\delta(\mathrm{OH})$ peaks for SA1 and SA2 appeared at 1615 and $1613 \mathrm{~cm}^{-1}$ and at 13.27 and $13.37 \mathrm{ppm}$, respectively. Electrodeposit both compounds on mild steel at $0.05 \mathrm{M}$ concentration in $0.3 \mathrm{M}$ $\mathrm{NaOH}$ was established through cyclic voltammetry (CV) and chronoamperometry (CA) methods. Yellow and brownish Schiff base layers were observed to be formed on the mild steel specimens. The coated and uncoated mild steel specimens were tested for their corrosion behavior using the Tafel Extrapolation Method (TEM) in $0.5 \mathrm{M} \mathrm{NaCl}$. Results demonstrated that mild steel coated with SA2 through CA technique at potential $+0.90 \mathrm{~V}$ showed the highest inhibition efficiency, hence indicating a superior surface coverage, with $97.20 \%$ inhibition efficiency; while SA1 recorded the highest inhibition efficiency of $93.83 \%$ at coating potential of $+1.35 \mathrm{~V}$.
\end{abstract}

Keywords: chronoamperometry; corrosion inhibition; cyclic voltammetry; electrodeposition; Schiff base

\section{Introduction}

Schiff bases were first reported by a German scientist named $\mathrm{Hu}-$ go Schiff in 1864 [5] which contain characteristic $\mathrm{C}=\mathrm{N}$ functional group and are commonly synthesized through condensation of primary amines with active carbonyl compounds [1]. It shows high affinity for bonding with metal centres due to the presence of lone pair of electrons on the Schiff base nitrogen, and this affinity is enhanced by the presence of other lone pair bearing substituents such as $-\mathrm{OH}$ and $\mathrm{OCH} 3$. A broad range of applications of Schiff bases and their metal complexes have been reported by several studies, which including catalytic properties, bioactivity and corrosion inhibiting ability [12], [15], and [18].

Schiff bases possess as an effective anti-corrosion agents for protection of metals like mild steel, aluminium and copper surface [11], [19], [21]. The existence of electrodeposited layer of inert organic layer such as Schiff bases on mild steel surface can protect it from corrosive medium environment [13]. The selection of Schiff bases to be electrodeposited on mild steel surface for corrosion prevention is primarily based on two factors which are; (a) easily be produced using cheap raw materials and (b) containing electron rich moieties such as aromatic rings and/or the heteroatoms such as nitrogen, sulphur and oxygen [1]. On the other hand, sodium chloride $(\mathrm{NaCl})$ solution has been reported as an aqueous corrosion medium in many studies [6] in which typically set to be similar to that of seawater, which can mimic corrosive exposure of metals in offshore infrastructures and coastal areas. This condition is also widely applicable in different systems such as cooling systems, storage reservoirs and water and fuel pipelines [10].
The objective of this study are to synthesize and characterize two Schiff bases i.e. SA1 and SA2 which exhibiting very similar chemical structures except for the presence of - $\mathrm{OCH} 3$ in SA2 (Figure 1). Both compounds were electrodeposited on mild steel samples using two different techniques namely cyclic voltammetry $(\mathrm{CV})$ and chronoamperometry (CA). The corrosion behaviour of mild steel coated with SA1 and SA2 was studied in $0.5 \mathrm{M} \mathrm{NaCl}$ using Tafel Extrapolation Method (TEM) and compared with that of the uncoated mild steel. The difference of inhibition properties of the compounds can be explained based on the structures of SA1 and SA2. (a)

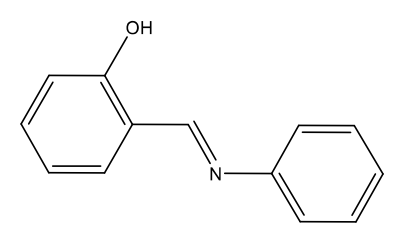

(b)

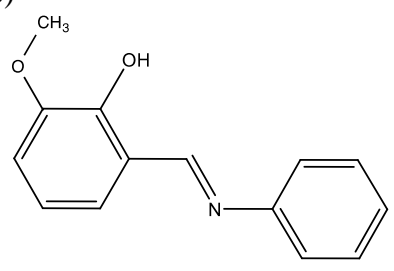

Fig. 1: Molecular structures of (a) SA1 and (b) SA2 


\section{Materials and Methods}

\subsection{Materials}

All the chemicals and solvents used were of analytical grade. Salicylaldehyde, o-vanilin, aniline, absolute ethanol, chloroform, deuterated chloroform $(\mathrm{CDCl} 3)$ and potassium bromide $(\mathrm{KBr})$. The microanalytical data $(\mathrm{C}, \mathrm{H}$ and $\mathrm{N})$ of SA1 and SA2 were obtained on Thermo Scientific Flash 2000 Elemental Analyzer. Melting points of both compounds were determined using Stuart SMP10. Perkin-Elmer model 1750X FTIR spectrophotometer using $\mathrm{KBr}$ pellets was employed to record infrared (IR) spectra of compounds in the range of $450-4000 \mathrm{~cm}^{-1}$. ${ }^{1} \mathrm{H}$ NMR spectra were recorded on a Bruker Varian- $600 \mathrm{MHz}$ spectrometer using deuterated chloroform $(\mathrm{CDCl} 3)$ and expressed in parts per million $(\delta$, $\mathrm{ppm}$ ) relative to internal reference of TMS.

\subsection{Materials}

\subsubsection{Synthesis and Characterization of Salicylidene-Aniline (SA1)}

A mixture of $20 \mathrm{mmol}$ of salicylaldehyde and $20 \mathrm{mmol}$ of aniline in absolute ethanol $(15 \mathrm{~mL})$ was refluxed for 3 hours upon which a yellow like precipitate was formed. The yellow precipitate was then filtered off and washed with cold ethanol. For drying purposes, the precipitate was then dried in air [7].

\subsubsection{Synthesis and Characterization of Ovan-Aniline (SA2)}

A mixture of $20 \mathrm{mmol}$ of o-vanillin and $20 \mathrm{mmol}$ of aniline in absolute ethanol $(15 \mathrm{~mL})$ was refluxed for 2 hours until an orangelike precipitate produced. The precipitate was filtered, washed thoroughly with cold ethanol and air dried.

\subsubsection{Electrodeposition of Schiff Bases on Mild Steel and Cor- rosion Test}

The preparation of electrodeposition technique and corrosion studies was retrieved by method done by [7] with slight modification were the concentration of each compounds were set to be $0.05 \mathrm{M}$.

\section{Results and Discussion}

\subsection{Compounds characterizations}

Table 1 shows the characterization results for both compounds Table 2 and Table 3 show results for NMR and IR, respectively, for both SA1 and SA2 compounds.

Table 1: Physicochemical properties of SA1 and SA2

\begin{tabular}{|c|c|c|c|}
\hline \multicolumn{2}{|c|}{ Compound } & $\mathrm{SA} 1$ & $\mathrm{SA} 2$ \\
\hline \multicolumn{2}{|c|}{ Molecular formula } & $\mathrm{C}_{13} \mathrm{H}_{11} \mathrm{NO}$ & $\mathrm{C}_{14} \mathrm{H}_{13} \mathrm{NO}_{2}$ \\
\hline \multicolumn{2}{|c|}{ Yield (\%) } & 80.74 & 83.16 \\
\hline \multicolumn{2}{|c|}{ Melting point $\left({ }^{\circ} \mathrm{C}\right)$} & $52-54$ & $90-92$ \\
\hline \multicolumn{2}{|c|}{ Colour } & Yellow & Orange \\
\hline \multirow{2}{*}{ Elemental analysis (\%) } & $\mathrm{C}$ & $78.16(79.16)$ & $\begin{array}{c}73.99 \\
(73.99)\end{array}$ \\
\cline { 2 - 4 } Experimental & $\mathrm{H}$ & $5.57(5.62)$ & $\begin{array}{c}5.54 \\
(5.77)\end{array}$ \\
\cline { 2 - 4 } (Theoretical) & $\mathrm{N}$ & $6.65(7.10)$ & $\begin{array}{c}5.92 \\
(6.16)\end{array}$ \\
\hline
\end{tabular}

According to ${ }^{1} \mathrm{H}$ NMR data in Table 2, the number of hydrogens obtained was in concordance with the structure. The $\delta(-\mathrm{OH})$ in SA1 and SA2 were found at 13.27 and $13.73 \mathrm{ppm}$, whereas $\delta(-$ $\mathrm{N}=\mathrm{CH}$ ), appeared at 8.63 and $8.66 \mathrm{ppm}$, respectively. The peak of $\mathrm{O}_{-} \mathrm{CH}_{3}$ in SA2 was observed at $3.97 \mathrm{ppm}$. The small recorded shifting of less than $1 \mathrm{ppm}$ described above, indicates that the presence of $-\mathrm{OCH}_{3}$ substituent on SA2 did not produce significant shielding effect on the $-\mathrm{OH}$ and $-\mathrm{N}=\mathrm{CH}$ protons.

Table 2: NMR values for SA1 and SA2

\begin{tabular}{|c|c|c|}
\hline Compound & Chemical Shift (ppm) & $\begin{array}{c}{ }^{1} \mathrm{H} \text { NMR } \\
\text { Assignment }\end{array}$ \\
\hline \multirow[b]{5}{*}{ SA1 } & $8.63(s, 1 \mathrm{H})$ & $-\mathrm{N}=\mathrm{CH}$ \\
\hline & $13.27(s, 1 \mathrm{H})$ & $\mathrm{O}-\mathrm{H}$ \\
\hline & - & $-\mathrm{O}-\mathrm{CH}_{3}$ \\
\hline & $\begin{array}{c}7.41-7.68 \\
(m, J=6-9 \mathrm{~Hz}, 4 \mathrm{H})\end{array}$ & Aromatic (A) \\
\hline & $\begin{array}{c}6.98-7.49 \\
(m, J=6-9 \mathrm{~Hz}, 5 \mathrm{H})\end{array}$ & Aromatic (B) \\
\hline $\mathrm{CH}_{3}$ & $8.66(s, 1 \mathrm{H})$ & $-\mathrm{N}=\mathrm{CH}$ \\
\hline & $13.73(s, 1 \mathrm{H})$ & $\mathrm{O}-\mathrm{H}$ \\
\hline & $3.97(s, 3 \mathrm{H})$ & $-\mathrm{O}-\mathrm{CH}_{3}$ \\
\hline & $\begin{array}{c}6.90-7.06 \\
(m, J=6-9 \mathrm{~Hz}, 3 \mathrm{H})\end{array}$ & Aromatic (A) \\
\hline SA2 & $\begin{array}{c}7.31-7.47 \\
(m, J=6-9 \mathrm{~Hz}, 5 \mathrm{H})\end{array}$ & Aromatic (B) \\
\hline
\end{tabular}

The values of coupling constants as shown in Table 3 are in the range of 6-9 Hz, suggesting the existence of ortho aromatic protons. These aromatic protons are greatly deshielded due to diamagnetic anisotropy contributed by circulating $\pi$-electrons in the aromatic rings.

As shown in Table 3, the signature infrared peak, $v(\mathrm{C}=\mathrm{N})$, of Schiff bases were detected as strong bands at 1615 and $1613 \mathrm{~cm}^{-1}$ for SA1 and SA2, respectively. The $v(\mathrm{C}-\mathrm{N})$ peaks were found at $1268-1274 \mathrm{~cm}^{-1}$, slightly higher than those of $v(\mathrm{C}-\mathrm{O})_{\text {methoxy }}$ and $v(\mathrm{C}-\mathrm{O})_{\text {phenol }}$ that appeared at $1152-1253 \mathrm{~cm}^{-1}$, obeying the Hooke's Law mentioned by [4], where the molecular weight of functional group is inversely proportional with frequency or wavenumber. Thus, the higher the molecular weight the lower the frequency. The presence of $-\mathrm{OCH}_{3}$ in $\mathrm{SA} 2$ can be identified from the characteristic weak peak at $2900 \mathrm{~cm}^{-1}$ and a strong peak at $1253 \mathrm{~cm}^{-1}$, assignable to $\mathrm{OCH}_{3}$ and $\mathrm{C}-\mathrm{O}$ vibrations, respectively. The $\mathrm{OH}$ functional groups in both compounds are accounted for by the $v(\mathrm{O}-\mathrm{H})$ and $v(\mathrm{C}-\mathrm{O})$ in the regions of $3077-3131 \mathrm{~cm}^{-1}$ and $1152-$ $1166 \mathrm{~cm}^{-1}$, respectively.

Table 3: Pertinent infrared data for SA1 and SA2

\begin{tabular}{|c|c|c|}
\hline \multirow{2}{*}{ Functional group } & \multicolumn{2}{|c|}{ Frequency $\left(\mathrm{cm}^{-1}\right)$} \\
\cline { 2 - 3 } & SA1 & SA2 \\
\hline $\mathrm{C}=\mathrm{N}$ & 1615 & 1613 \\
\hline $\mathrm{C}-\mathrm{N}$ & 1274 & 1268 \\
\hline $\mathrm{C}=\mathrm{C}$ & 1482 & 1465 \\
\hline $\mathrm{OCH}_{3}$ & - & 2900 \\
\hline $\mathrm{C}-\mathrm{O}$ (methoxy) & - & 1253 \\
\hline $\mathrm{C}-\mathrm{O}$ (phenol) & 1152 & 1166 \\
\hline $\mathrm{O}-\mathrm{H}$ & 3131 & 3077 \\
\hline $\mathrm{Ar}-\mathrm{H}$ & 3054 & $3000-3100$ \\
\hline
\end{tabular}

\subsection{Electrodeposition of SA1 and SA2 on Mild Steel}

Cyclic voltammetry (CV) method was used to electrodeposit both compounds on mild steel. Figure 2 shows the cyclic voltammograms of SA1 and SA2 during electrodeposition. The scan potential range used was $0 \mathrm{~V}$ to $+2 \mathrm{~V}$ and back to $0 \mathrm{~V}$ with a scan rate of $0.1 \mathrm{~V} / \mathrm{s}$. Five CV cycles were carried out for both compounds with a yellow layer was observed to formed on the surface of mild steel when coated with SA1. Furthermore, a brownish layer was formed when coated with SA2 at the end of the cycles. During the deposition of both compound on mild steel via $\mathrm{CV}$, the first cycles of SA1 and SA2 displayed a similar behaviour, which when the current increased, reached a maximum and decreased. In Figure 2, the current was observed to become much lower after the first cycle as the current suppression started to occur. The magnitude of current suppression decreased progressively from the second to fifth cycle. This indicates that the active sites of anode (mild steel) gradually became passivated after the first cycle, reducing electron transfer and decreasing electrodeposition 


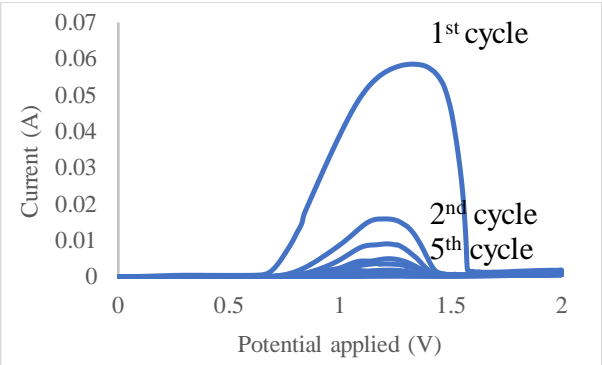

Fig. 2: Cyclic voltamograms of mild steel in $0.3 \mathrm{M} \mathrm{NaOH}$ during deposition of SA1 coating

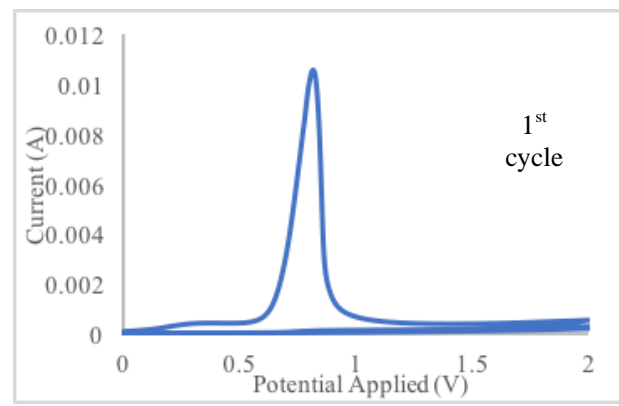

Fig. 3: Cyclic voltamograms of mild steel in $0.3 \mathrm{M} \mathrm{NaOH}$ during deposition of SA2 coating

However, for the compound SA2, the current at maximum peak was lower than that of SA1 indicating that SA2 required less current than SA1 to be deposited on mild steel surface, a sign of higher affinity to electropositive metal. The second cycle recorded a very low current reading of approximately $0 \mathrm{~A}$ with no maximum current peak shown in Figure 3. This behaviour revealed that almost perfect surface coverage of mild steel by SA2 had occurred after the first cycle.

Another technique by chronoamperometry (CA) method was also used to electrodeposit both compounds on mild steel. Three potentials were used based on the onset, maximum peak and offset values in the cyclic voltammogram of each compound. Figure 3(a) shows the chronoamperometric curves at the three different potentials of $+0.8 \mathrm{~V},+1.30 \mathrm{~V}$ and $+1.60 \mathrm{~V}$ for SA1 and Figure $3(\mathrm{~b})$ shows three different potentials at $+0.68 \mathrm{~V},+0.82 \mathrm{~V}$ and $+0.87 \mathrm{~V}$ for SA2. The CA method was carried out in $0.3 \mathrm{M} \mathrm{NaOH}$ that contained $0.05 \mathrm{M} \mathrm{SA} 1$ and $0.05 \mathrm{M} \mathrm{SA} 2$ for 15 minutes of deposition. Current reduction was detected during the 15 minutes of deposition.

For SA2, stationary current was achieved after approximately 3 minutes (180 seconds) for all deposition potentials used until deposition completed. However, for SA1, the stationary current was achieved after 3 minutes (180 seconds) for potentials $+0.80 \mathrm{~V}$, and 1 minute ( 60 seconds) for $+1.30 \mathrm{~V}$ and $+1.50 \mathrm{~V}$. This shows that inhibitive layer of SA2 formed faster than SA1, in agreement with the observation made previously by $\mathrm{CV}$ method. Current reduction represents the electrochemical process of the film on the metal surface, indicating the adsorption strength of coating on the surface, where the smaller the current the better the metal electrode polarization will be, hence improve corrosion inhibition efficiency. Based on chronoamperometric curves as shown in Figure 4 (SA1) and Figure 5 (SA2), it is interesting to note that SA2 need less current roughly about $50 \%$ than SA1 for the deposition to occur.

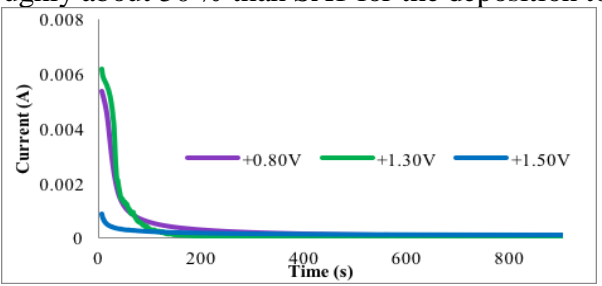

Fig. 4: Chronoamperometric curves of mild steel coated with $0.05 \mathrm{M}$ of $\mathrm{SA} 1$ and in $0.3 \mathrm{M} \mathrm{NaOH}$

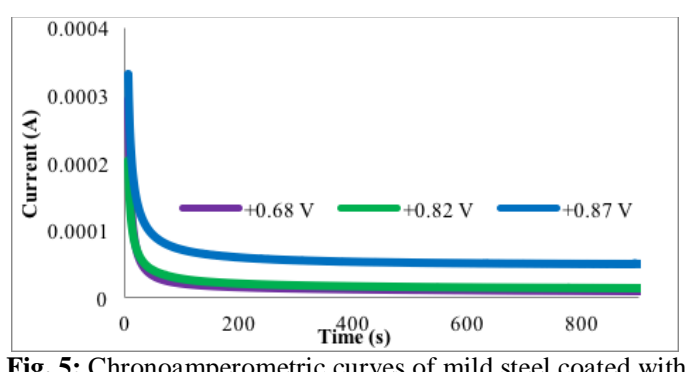

Fig. 5: Chronoamperometric curves of mild steel coated with $0.05 \mathrm{M}$ of SA2 and in $0.3 \mathrm{M} \mathrm{NaOH}$

\subsection{Tafel Extrapolation Studies}

The Tafel plots of the blank (i.e. uncoated mild steel) and the mild steel electrodeposited with SA1 and SA2 via CV method are presented in Figure 4, while for CA technique in Figure 5. In principle, a displacement of corrosion potential $\left(\mathrm{E}_{\mathrm{corr}}\right)$ of more than +85 $\mathrm{mV}$ with respect to corrosion potential of blank classifies the inhibitor as anodic type whereas a displacement of more than -85 $\mathrm{mV}$ classifies it as a cathodic type inhibitor [8] and [14]. Any displacement values between +85 to $-85 \mathrm{mV}$ indicate a mixed-type protective coatings, as the case was with both SA1 and SA2 (Table 4). Based on Figure 4, the Tafel plot of mild steel coated with SA1 slightly shifted to positive direction while that of SA2 shifted to negative direction revealing that SA1 predominantly controlled by anodic reactions while SA2 controlled by cathodic ones when coated via $\mathrm{CV}$ method.

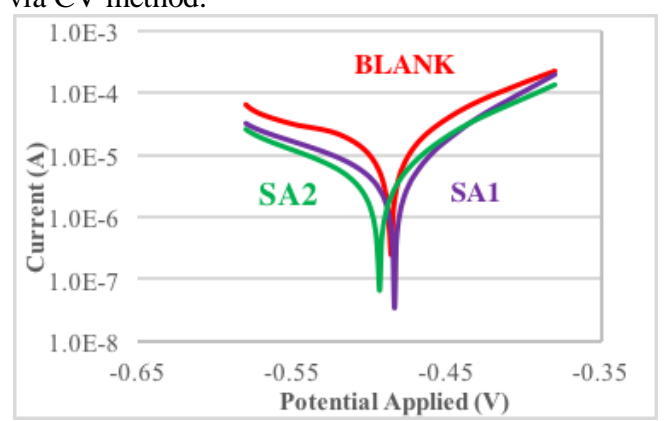

Fig. 6: Tafel plot of uncoated and coated mild steel using CV with SA1 and $\mathrm{SA} 2$ in $0.5 \mathrm{M} \mathrm{NaCl}$

The values of all electrochemical parameters i.e. anodic Tafel slope $\left(\beta_{\mathrm{a}}\right)$, cathodic Tafel Slope $\left(\beta_{\mathrm{c}}\right)$, corrosion potential $\left(\mathrm{E}_{\mathrm{corr}}\right)$, corrosion current density $\left(\mathrm{l}_{\text {corr }}\right)$, corrosion rate $(\mathrm{mm} / \mathrm{yr})$, and polarization resistance $(\mathrm{k} \Omega)$ are listed in Table $4(\mathrm{SA} 1)$ and Table 5 (SA2). The inhibition efficiency (IE \%) of SA1 and SA2 was calculated using the following equation [2].

$I E \%=\frac{i_{\text {corr }}-i_{\text {corr }}}{i_{\text {corr }}^{\circ}} \times 100$

Where, $i_{\text {corr }}^{\mathrm{o}}$ and $i_{\text {corr }}$ are uncoated and coated current densities, respectively.

It can be observed that $\beta_{\mathrm{a}}$ values were more affected for both compounds than that of $\beta_{c}$, indicating that the anodic reaction was more affected than the cathodic reaction. This indicates that the inert layer coated on mild steel immersed in near neutral solution can retards both anodic dissolution of mild steel as well as reduction at cathodic sites in corrosion prevention process [20].

The presence of protective layer increased the polarization resistance of mild steel in $0.5 \mathrm{M} \mathrm{NaCl}$ which lead to reduction in corrosion current [17]. The current densities $\left(i_{\text {corr }}\right)$ were shifted to lower values for both anodic and cathodic Tafel curves indicates that these suppressions affect the anodic reaction current with both water and hydrogen cathodic evolution reactions. A decrease in $i_{\text {corr }}$ had been reported to cause an increase in inhibition efficiency due to an increase in the blocked fraction of the mild steel surface by adsorption of the compounds [3] and [9]. 
Table 4: Tafel Extrapolation results of uncoated and coated mild steel with $\mathrm{SA} 1$ using $\mathrm{CV}$ and $\mathrm{CA}$ techniques.

\begin{tabular}{|c|c|c|c|c|c|}
\hline Compound & Blank & $\begin{array}{l}\text { SA1 } \\
(\mathrm{CV})\end{array}$ & \multicolumn{3}{|c|}{ SA1 (CA) } \\
\hline Potential (V) & - & $0-2-0$ & +0.80 & +1.30 & +1.50 \\
\hline $\begin{array}{c}\beta_{\mathrm{a}} \\
(\mathrm{mV} / \mathrm{dec})\end{array}$ & 672.97 & 145.13 & 250.83 & 140.58 & 409.43 \\
\hline$\beta_{\mathrm{c}}(\mathrm{mV} / \mathrm{dec})$ & 127.95 & 63.23 & 80.30 & 118.97 & 893.94 \\
\hline $\begin{array}{l}E_{\text {corr }} \\
(\mathrm{mV})\end{array}$ & $\begin{array}{c}- \\
486.01 \\
\end{array}$ & $\begin{array}{c}- \\
463.97 \\
\end{array}$ & 546.69 & 439.26 & $\begin{array}{c}- \\
404.88 \\
\end{array}$ \\
\hline$i_{\text {corr }}\left(\mu \mathrm{A} / \mathrm{cm}^{2}\right)$ & 37.45 & 5.97 & 11.73 & 2.18 & 10.22 \\
\hline $\begin{array}{c}\text { Corrosion rate } \\
(\mathrm{mm} / \text { year })\end{array}$ & 0.4351 & 0.0694 & 0.1363 & 0.0254 & 0.1187 \\
\hline $\begin{array}{c}\text { Polarization resistance } \\
(\mathrm{k} \Omega)\end{array}$ & 1.247 & 3.202 & 2.249 & 12.829 & 11.937 \\
\hline $\begin{array}{c}\text { Inhibition efficiency } \\
(\%)\end{array}$ & & 84.05 & 68.67 & 94.17 & 72.72 \\
\hline
\end{tabular}

Table 5: Tafel Extrapolation results of uncoated and coated mild steel with SA2 using CV and CA techniques.

\begin{tabular}{|c|c|c|c|c|c|}
\hline Compound & Blank & $\begin{array}{c}\text { SA2 } \\
(\mathrm{CV})\end{array}$ & \multicolumn{3}{|c|}{ SA2 (CA) } \\
\hline Potential (V) & - & $0-2-0$ & +0.68 & +0.68 & +0.85 \\
\hline $\begin{array}{c}\beta_{\mathrm{a}}(\mathrm{mV} / \mathrm{dec}) \\
\beta_{\mathrm{c}}(\mathrm{mV} / \mathrm{dec})\end{array}$ & 672.97 & 166.37 & 106.34 & 99.90 & 93.53 \\
\hline $\mathrm{E}_{\text {corr }}(\mathrm{mV})$ & 486.95 & 72.89 & 106.09 & 123.32 & 55.54 \\
\hline$i_{\text {corr }}\left(\mu \mathrm{A} / \mathrm{cm}^{2}\right)$ & 37.45 & 509.76 & 429.87 & 408.79 & 417.96 \\
\hline $\begin{array}{c}\text { Corrosion rate } \\
(\mathrm{mm} / \mathrm{year})\end{array}$ & 0.4351 & 0.0661 & 0.0404 & 0.0162 & 0.0175 \\
\hline $\begin{array}{c}\text { Polarization re- } \\
\text { sistance }(\mathrm{k} \Omega)\end{array}$ & 1.247 & 3.871 & 6.628 & 17.215 & 10.026 \\
\hline $\begin{array}{c}\text { Inhibition efficiency } \\
(\%)\end{array}$ & - & 84.81 & 90.71 & $\mathbf{9 6 . 2 8}$ & 95.97 \\
\hline
\end{tabular}

The lowest inhibition efficiency, IE, of $68.67 \%$ was recorded for mild steel coated with SA1 using CA coating techniques at potential $+0.80 \mathrm{~V}$; while the highest of $96.28 \%$ was observed for mild steel coated with SA2 using CA techniques at potential $+0.82 \mathrm{~V}$. This was a firm indication of the formation of a stable adsorbed SA2 layer on the mild steel surface.

Within the investigation protocol employed, SA1 and SA2 revealed inhibition efficiency, IE, ranges from $68.67 \%$ until $94.17 \%$ and $84.81 \%$ until $96.28 \%$, respectively. The values indicate that both ligands have good corrosion protection efficiency for mild steel in $0.5 \mathrm{M} \mathrm{NaCl}$, with $\mathrm{SA} 2$ being the better inhibitor. This is likely due to the presence of electron rich moieties in the form of $\pi$-electrons and lone electron pairs that greatly facilitate adsorption on mild steel namely the $\mathrm{C}=\mathrm{N}$ groups, aromatic rings, conjugated double bonds and heteroatoms present in both structures. Inhibition efficiency of both compounds was enhanced by the presence of hydroxyl substituents on the aromatic ring and even more by the addition of - $\mathrm{OCH} 3$ substituent on SA2.

Both hydroxyl and methoxy are electron donating groups that increase electron density of the aromatic ring as well as nitrogen in azomethine group via inductive effect, activating them for adsorptivity and assisting the process of electrodeposition on the mild steel substrate, hence giving them high inhibition efficiency. The lone pairs of electrons supplied by azomethine $\mathrm{N}$, hydroxyl $\mathrm{O}$ and methoxy $\mathrm{O}$ helped the compounds to adsorb more efficiently on mild steel surface, presumably as anchoring points.

\section{Conclusion}

Both Schiff bases, SA1 and SA2 were successfully synthesized and characterized by IR, 1HNMR, melting point and elemental analysis. Electrodeposition using cyclic voltammetry and chronoamperometry techniques resulted in formation of films on mild steel surface. Corrosion inhibition studies using Tafel Extrapolation Method showed that both compounds have good inhibition properties. The highest inhibition efficiency was recorded for mild steel coated with SA2 using CA techniques at $+0.82 \mathrm{~V}$ with $96.28 \%$ efficiency corresponding to $0.016178 \mathrm{~mm} / \mathrm{yr}$ corrosion rate, while the inhibition efficiency of SA1 Schiff base on corrosion of mild steel in $0.5 \mathrm{M} \mathrm{NaCl}$ was lower than mild steel coated with SA2. The highest inhibition efficiency by SA1 was $94.17 \%$ with mild steel coated at $+1.30 \mathrm{~V}$. The number of electron donating substituents on the molecule seem to be directly proportional to the inhibition efficiency. The presence of two electrons donating groups in SA2 compound activated the overall compound for adsorption on mild steel more effectively than SA1.

\section{Acknowledgement}

Authors are highly thankful to the Ministry of Higher Education, Malaysia and the Faculty of Applied Sciences, Universiti Teknologi MARA for the research grant 600IRMI/MyRA5/3/BESTARI (034/2017), scholarship and the research facilities.

\section{Reference}

[1] Abbas, M. A., Zakaria, K., Hamdy, A., \& El-azabawy, O. E. (2015) Synthesis of Novel Schiff Base Silicon Compound for Employing as Corrosion Inhibitor for Carbon Steel in the $1 \mathrm{M} \mathrm{HCL}$ and, 3(2). Abd El-Rehim, S. S., Ibrahim, M. A. M., \& Khaled, K. F. (1999). 4-Aminoantipyrine as an inhibitor of mild steel corrosion in $\mathrm{HCl}$ solution. Journal of Applied Electrochemistry, 29(5), 593-599.

Balaji, M., Chandrasekar, N., Sharmila, G., \& Manivannan, R. (2016). Synthesis and evaluation of Anti-Corrosive Behaviour of Some Schiff Base Derivatives. International Journal of Research in Engineering \& Technology, 4(6), 51-64.

[4] Burke, J. T. (1997). IR Spectroscopy or Hooke's Law at the Molecular Level - A Joint Freshman Physics-Chemistry Experience. Journal of Chemical Education, 74(10), 1213.

[5] Cimerman, Z., Miljanić, S., \& Galić, N. (2000). Schiff Bases Derived from Aminopyridines as Spectrofluorimetric Analytical Reagents. Croatica Chemica Acta, 73(1), 81-95.

[6] Cui, B., Yan, H. J., Wang, D., \& Wan, L. J. (2013). The structural details and substituent effects on biphenyls adlayers with halogen/pseudohalogen substituents on Au(111): An STM investigation. Journal of Electroanalytical Chemistry, 688, 237-242.

[7] Dzolin, S. A., Mohd, Y., \& Bahron, H. (2017). Corrosion Inhibition of Azomethines Containing Hydroxyl Group at Ortho and Para Positions on Mild Steel. Pertanika Journal of Science and Technology, 25(1), 317-324.

[8] Farag, A. A., Migahed, M. A., \& Al-Sabagh, A. M. (2015). Adsorption and inhibition behavior of a novel Schiff base on carbon steel corrosion in acid media. Egyptian Journal of Petroleum, 24(3), 307-315.

[9] Gunavathy, N., \& Murugavel, S. C. (2013). Corrosion inhibition study of bract extract of Musa acuminata inflorescence on mild steel in hydrochloric acid medium. IOSR Journal of Applied Chemistry, 5(2), 29-35.

[10] Ma, F., Li, W., Tian, H., Kong, Q., \& Hou, B. (2012). Inhibition behavior of chito-oligosaccharide schiff base derivatives for mild steel in $3.5 \% \mathrm{NaCl}$ solution. International Journal of Electrochemical Science, 7(11), 10909-10922.

[11] Muthu Saravana Bagavathy, S., \& Ganesan, P. . (2015). Corrosion inhibition studies on Schiff bases derived from 2-amino-, 7(2), 830-839.

[12] Nor Hashim, N. Z., \& Kassim, K. (2014). The effect of temperature on mild steel corrosion in $1 \mathrm{M} \mathrm{HCl}$ by Schiff bases. The Malaysian Journal of Analytical Sciences, 18(1), 28-36

[13] Ravari, F. B., \& Dadgarinezhad, A. (2012). New Synthesized Schiff base as Inhibitor of Mild Steel Corrosion in Acid Medium, 25(4), $835-842$.

[14] Riggs, O. L. (1975). Second Anodic Current Maximum for Type 430 Stainless Steel in 0. 1N H//2So//4. Corrosion.

Şafak, S., Duran, B., Yurt, A., \& Türkoĝlu, G. (2012). Schiff bases as corrosion inhibitor for aluminium in $\mathrm{HCl}$ solution. Corrosion Science, 54(1), 251-259.

[16] Scendo, M., \& Trela, J. (2013). Corrosion Inhibition of Carbon Steel in Acid Chloride Solution by Schiff Base of $\mathrm{N}-(2$ chlorobenzylidene ) -4-acetylaniline, 8, 8329-8347.

[17] Thirugnanaselvi, S., Kuttirani, S., \& Emelda, A. R. (2014). Effect of Schiff base as corrosion inhibitor on AZ31 magnesium alloy in hydrochloric acid solution. Transactions of Nonferrous Metals Society of China, 24(6), 1969-1977. 
[18] Venkata, B., Rao, A., Rao, M. V., Rao, S. S., \& Sreedhar, B. (2013). Surface Analysis of Carbon Steel Protected from Corrosion by a New Ternary Inhibitor Formulation Containing Phosphonated Glycine , Zn 2 + and Citrate. Journal of Surface Engineered Materials and Advanced Technologu, 3(January), 28-42.

[19] Zainoldin, Z., Harun, M. K., Bahron, H., \& Kassim, K. (2012). Electrodeposition of Salicylideneaniline and its Corrosion Behavior Advanced Materials Research, 554-556, 385-389.

[20] Zakaria, K., Negm, N. A., Khamis, E. A., \& Badr, E. A. (2016) Electrochemical and quantum chemical studies on carbon steel corrosion protection in $1 \mathrm{M} \mathrm{H} 2 \mathrm{SO} 4$ using new eco-friendly Schiff base metal complexes. Journal of the Taiwan Institute of Chemical Engineers, 61, 316-326.

[21] Zhang, J., Liu, Z., Han, G. C., Chen, S. L., \& Chen, Z. (2016). Inhibition of copper corrosion by the formation of Schiff base selfassembled monolayers. Applied Surface Science, 389, 601-608. 